\title{
A Model for Competency Assessment of the Faculty in Islamic Azad University
}

\author{
Aliasghar Mashinchi ${ }^{1}$, Seyed Ahmad Hashemi ${ }^{2}$ \& Kamran Mohammad Khani ${ }^{1}$ \\ ${ }^{1}$ Department of Higher Education Management, Science and Research Branch, Islamic Azad University, Iran \\ ${ }^{2}$ Department of Education, Lamerd Branch, Islamic Azad University, Iran \\ Correspondence: Aliasghar Mashinchi, Department of Higher Education Management, Science and Research \\ Branch, Islamic Azad University, Tehran, Iran. E-mail: a.mashinchi@srbiau.ac.ir
}

\author{
Received: June 15, $2016 \quad$ Accepted: July 22, $2016 \quad$ Online Published: February 27, 2017 \\ doi:10.5539/ies.v10n3p76 URL: https://doi.org/10.5539/ies.v10n3p76
}

\begin{abstract}
Today country success in economic, social, political, cultural tendencies etc. ... is approved to be the hostages and pawns of coherent and dynamic didactic system. The education and didactic programs for qualification improvement and dynamism need to quantitatively and qualitatively evaluation and scrutiny. Current study started with the goal of presenting faculty competency evaluation for the reason of qualitative improvement of Islamic Azad University. Research in terms of to the way of collecting and compiling the details descriptivesurvey and in terms of the goal and target type is so practical that by conducting general scrutiny in literature and subject history and past, we drawn the theoretical frame and conceptual model in this study. Nominee educational members' opinions faculty members (self-assessment), supervisors (superiors), students of (clients) Fars province different Islamic Azad Universities are as the research society. In this research, with researcher evaluation in 24 active units in Fars province, approximately 125000 persons were examined. That sample volume was selected equal to 380 persons by using the clustered random sampling method (Krejcie and Morgan formulas). For collecting data, we used a researcher-made questionnaire whose validity was confirmed by the specialists and its stability was calculated by using the Cronbach's alpha method equal to 0.84 . Researcher-made questionnaire includes effective component in competency in five general axes for collecting the data. Then, with using 360-degree evaluation method, it was executed. For the data analysis, we used the descriptive statistic method and elicitation statistic (fact oral analysis, Wilcoxon and Friedman) and the results of the study are as follows: 1. drawing the model of competency evaluation of faculty (main dimension of evaluation indexes of faculty competencies), and 2. In the field of evaluation of the current situation from the dimensions and competence skill parameters, the ethical values, role, personal, and favorable statuses are evaluated. But in the performance and functional dimensions, and its subcomponents unfavorable status and lower than average level evaluated and the results of ranking of evaluation of dimensions of competencies of faculty in order to select the most priority is related to skill dimension, and the least priority is related to the functional and performance dimensions.
\end{abstract}

Keywords: competency, faculty, evaluation

\section{Introduction}

According to the society gradual conversion to knowledge-based society, the social demand for knowledge and skills has increased. Moreover, universities throughout the world inevitably have been qualitatively and quantitatively spread (Noorshahi, 2008). With growing the importance of higher education (palpitate heart and society development motor) and its high development in societies and doing various missions, most of them have reached the point that university means faculty. This work led to decrease in the options level of faculty and power of the faculty in the main operation of the university (Ferasatkhah, 2009); hence, faculty is considered as an undertaking main and effective educational pillar in the higher education system operation and its targets substantiation. On the other hand, education system of every country by accompanying with evaluation, research, and examination processes can be able to protect and develop the performance and effectiveness and answerer to the needs of labor market and accountable to labor market, and accountable to procedure of growth of economic, social, and cultural pillars of society. Thus, faculty evaluation is a way to increase the universities quality and society's progress and development. 
Evaluation is an aspect and of course important aspect of educational activities, and we can realize the shortcomings and strength points of the educational plans and offer suitable solutions to solve the educational plan problems.

In this case, teacher evaluation is an important strategy for education quality improvement, and it is attractive for the universities. For this reason, higher education centers determine some criteria for detecting the teacher competency and hereby in this way, with a good process, they will evaluate their performance. Pundits have offered that for final augmentation, paying attention to the different aspects of evaluation that the affair needs is a general pattern (Mousapour, 2002, p. 120).

Jirouk et al. (1998) have scurried the evaluation reliability and validity of teachers from students and have come to the result that students evaluation depends on teachers' coaching ability and detectable teaching ability and detectable teaching skills (Jafari \& Hedayat, 2014, p. 5).

It is necessary to have faculty competency model for hinting employment, instruction and evaluation in the universities; and it can be framework for management in the basis of competency in organization for improvement. A competency evaluation pattern includes table of competencies that are prepared by looking at the satisfactory performance of a special job. This pattern can detect the competencies that persons should develop for improving the performance in their current job and, or for promotion or transferring to the other jobs. In skills fracture analysis, means compartment between available competencies and needed competencies, this pattern can also be profitable (Mousapour, 2002, p. 119)

Texts scrutiny shows that the special evaluation model for faculty competency evaluation in the higher education system of Iran does not exist and the important benefits are as follows:

Level and size of vocational and personal competency in the higher education system can be determined prepress, a framework to evaluate their performance quality.

The role of higher education in country development is very important (society's development motor).

The main component of the universities is faculty. The faculty competency levels have much affection on higher education performance. Faculty competency's influence on learning level, progress, and satisfactory of the students according to qualitative problems of Iran's higher education and cheap upper cases, the researcher likes to draw and illustrate the faculty evaluation model in the Islamic Azad University in the country. The data of the model is useable for all zones of decision; so that in the future, we will see qualitative progress in the higher education system of Iran and the various problems will decrease the wishing goal of this study which is to promote higher education quality in Iran by making the faculty competency evaluation model in the Islamic Azad university.

\section{History}

The most important done insiders and outsiders' evaluations in the study subject are as follows:

Robert et al. (2009) believe that the teaching competencies of the members of the faculty include seven dimensions: to prepare favorable learning environment, to actively get involve the students, the knowledge of evaluation, students' skill and view, easy access to the educational goals for the students, giving the feedback to the students, competency level awareness, self- teaching ability awareness, self-directed training, and lifetime learning.

Vishan (1999) says that six skill dimensions: vocational knowledge, planning for teaching and education, execution of educational strategies, resource and manpower management, student learning level evaluation, vocational responsibility are the important skills for an effective teaching.

Patrick and Smart (1998) believe that the effectiveness of the faculty members in the classroom involves various dimensions including sole dimensions like respecting the students, ability to challenge the students, mind stimulation of the students, lesson organization, speech skills, representation of reviewing the lectures.

Smith (2010) gained the competency parameters from the oral fact analysis. He refined in the basis of reviewing the texts, primary study, feedback from elites, questionnaire in this corrected competency model based on empirical data presented for higher education leader.

This model presents fire distinct and separate competency dimension: (HELC)

1) Analytical dimension

2) Communications

3) Affairs related to the student-dimension. 
4) Behavioral relationship dimension.

5) External relationship dimension.

\section{Analytical Competencies}

Jonson (2003) presented a triangular competency structure for teacher. This model includes three main components:

1) Identical/operational competency

2) Behavioral or personal competency

3) Cognitive/ knowledge competency

4) Ethical competency

Miller (2006) believes that the types of competence are necessary for university professors, as follows:

a) technical competence and ability (Science and skill in teaching lessen)

b) vocational competence and ability (plan awareness, educational, evaluation, and presentation)

c) personal and sole competence (personal properties effective behavior in training and upbringing process)

Kember and Jones (1996) in a study with the subject: worldwide view on educational goal, teaching, and evaluation goal gain the results that the world's higher educational system is going through quality of faculty member teaching. Hence, it is required to make the mechanisms for evaluating the teaching quality in a standard mode. One of the important indices of education evaluation is the faculty teaching quality.

Hojati (1999) approved that evaluation of faculty members for teaching quality was more important, because making professional forces for the future generation requires strong faculty in the universities either in their education or in their own knowledge in research, view, and conversance.

Reputation and reliability of higher education institutes depend on reliability and performance of their faculties. Workers performance evaluation influences the efficiency level promotion.

Jebeli (2004) illustrated that effort and stimulus of professors and teachers of university; in the case that there exists an index for comparing themselves to the other colleagues, it is better and more favorable. Whereas lack of these systems has resulted that, there is no difference between performances of professors and their salaries and benefits. Moreover, consequently, the better performance stimulus decreases. Human resources performance is the main pillar to protect and survive any organization.

Bazargan (2005) showed that universities as the organizations with the goal of making professional and special human resource beside and next to producing science, requires to evaluate their faculty members performance more than any other organization. Faculty evaluation results appear the weakness and strength points and are the start point of science development and achieving university goals.

Arasteh (2005) proved that a general system and a precise system of faculty members' performance evaluation can have favorable various effects such as: education requirements determination of human resources requirements, and the way to promote, sway and benefits determination of faculty members.

\section{Study Question}

1) What are the main parameters of faculty competency evaluation model at Islamic Azad University system?

2) How much are the parameters at the current status of faculty of Islamic Azad University?

3) How much is the coordination degree of the proposed model in specialists' opinion?

Method of research (statistic society, sample, method of sampling)

The Type of target of this study is practical, and evaluating how to collect the data is descriptive. According to the subject that the goal of this study is practically scientific knowledge, the researchers are practical (Sarmad, Bazargan, \& Majazi, 1999, p. 72).

With paying attention to the goal of this study which is compiling a model for evaluating the faculty competency in the first region (zone = number 1) of Islamic Azad University, the standardizing and compiling of these dimensions are at the local level. Because the researcher uses 360-degree feedback evaluating method, the statistic society of the study formed by educational stakeholders opinions (faculty members (examined), supervisors (group managers, educational assistants, students), students (clients) in various branches of Islamic Azad University in Fars province that with primary researcher evaluations at 24 active branches at Fars province, 
it became approximately 125000 persons. In this study, Krejcie and Morgan formulas are used to determine the sample volume and it has been estimated equal to 380 persons for primary evaluation. To select the statistical samples, the local random sampling method is used. First, Fars province was divided into 5 zones of north, east, west, south, and center; then, among the related branches of each zone, we selected the members of the desired sampling society by using random sampling methods. The following table shows zones and sample size in the selected branches:

Table 1. Zones and sample size in the selected branches

\begin{tabular}{ccccc}
\hline Geographic zone & Selected branches & Statistical sampling volume & Percent & Sample Size \\
\hline North & Abade & 28047 & 21.5 & 82 \\
South & Larestan & 16958 & 16 & 60 \\
East & Neyriz & 26170 & 20.5 & 78 \\
West & Shiraz & 41510 & 28 & 107 \\
Center & Jahrom & 12811 & 14 & 53 \\
Total & & 125496 & 100 & 380 \\
\hline
\end{tabular}

\subsection{Data Collecting Tools (Validity and Reliability)}

Researcher-made questionnaire is used to collect the data in this study; thus, in the direction of the goals a questionnaire is marked and completed. It is required to mention that internet network is used to determine the faculty competency evaluations and dimensions, with considering the past studies and researches on professors and specialists' opinion, and to search in databases.

In addition, factors and parameters are defined as a researcher-made questionnaire. For each of the parameters, some index as $s$ sub-parameter is considered; total of indices includes 5 main dimensions at 110 secondary parameter validity of measurement tool and the other important items in the method of research. Reliability of the measurement tool determined nominal by using item analysis.

For nominal validity, we interviewed with professors and specialists and brought their opinions in the questionnaire. Eleven professors and specialist confirmed and verified the validity of the tool. Furthermore, to ensure about the tool structure validity, after collecting the data, we evaluated it with fact oral analysis. The results obtained from the item analysis are shown in Table 2.

We can easily see that all evaluation tool items of faculty competencies in the organization are between 0.54 and 0.62 and at the significance level is 0.0001 .

Moreover, the total grade of the faculty competencies which have positive and significant relationship, it is illustrated the high validity of these items.

Table 2. The tool's validity table for faculty competencies

\begin{tabular}{cccc}
\hline Row & Sub parameter & Validity & Significance level \\
\hline 1 & Performance & $0.55-0.65$ & Significance level \\
2 & Skill & $0.48-0.56$ & 0.0001 \\
3 & Ethical & $0.54-0.60$ & 0.0001 \\
4 & Role & $0.48-0.56$ & 0.0001 \\
5 & Personal and sole & $0.55-0.65$ & 0.0001 \\
& The total grade & $0.54-0.62$ & 0.0001 \\
\hline
\end{tabular}

One of the important subjects in the study method is stability of the measurement tool. Measurement tool stability is a degree in which the obtained result could be resulted from repeating measurements. In other words, to use measurement tool in the same statuses and situations, and to evaluate the questionnaire reliability, Cronbach's alpha test is used. This test calculates the internal harmony in the questionnaire. In this method, after using SPSS software, Cronbach's alpha test was calculated.

Firstly, 30 questionnaires were randomly distributed between some individuals in the statistical society. At 2-week distance, the questionnaires given to them were collected.

Then, after using Cronbach's alpha, the reliability coordination was calculated. The results of the questionnaire 
test performing showed that questionnaire's questions had a high value of Cronbach's alpha coordination. The results relate to Cronbach's alpha test are indicated in Table 3.

Table 3. Cronbach's alpha results table

\begin{tabular}{ccccccr}
\hline Parameters & 1 & 2 & 3 & 4 & 5 & Total \\
\hline Reliability coordination & 0.79 & 0.83 & 0.93 & 0.76 & 0.86 & 0.84 \\
\hline
\end{tabular}

This table shows that the questions in the questionnaire were in line with the subject of the study and it had a good reliability.

\subsection{Data Analysis}

After making the questionnaire and collecting the answers, to analyze the obtained information, we used the descriptive statistic methods like abundance, abundance percent, abundance percent graph standard average, elicitation statistic (factor analysis, Wilkinson and Friedman). Data analysis processes and statistical tests were done by means of SPSS v.19 software.

\section{Discussion and Interpretation}

\section{The First Study Question:}

What are the main parameters of faculty competency evaluation at Islamic Azad University system?

For answering the above question, with scrutiny, the subject literature and history and the past five main dimensions of competency with special approach of this study are defined, its parameters by factor analysis test (Bartlet test, know, subscriptions table, component rotated matrix, factor naming) detected that indices or its sub parameters are as follows:

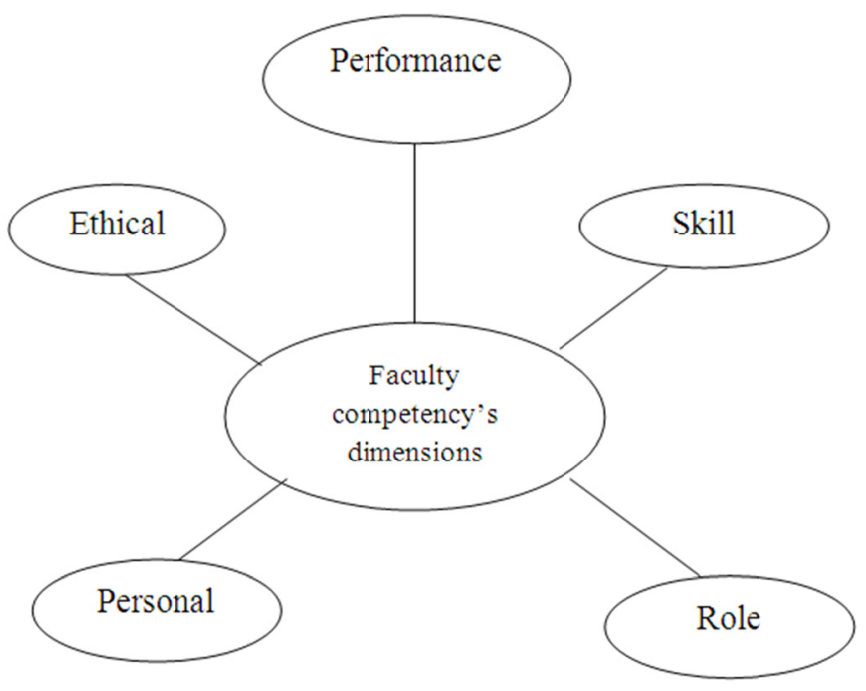

\subsection{Performance Dimension}

Parameter 1: Educational Planning

Indices:

- Ability to plan or the basis of orders and students scientific expectations

- Ability to plan to get evolve students' knowledge, skills, and thinking processes

- Using strategies, suitable processes, and various evaluations on educational plan

- Preparing the educational physical environment according to education type and learning type

- Plan to use technology as a tool to increase learning

- Using the university references and society references that support students to learn in the educational plan

- Using empirical educations that urge the student for versatility, flexibility, and creativity 
Parameter 2: Leading the education

Indices:

- Effective resources management ability to stable education development

- Detecting ability for various learning methods

- Harmonizing ability for stakeholders in university to access to high standards due to education

- Detecting the causes of students' misbehavior and doing something to correct it

- Supporting the standard upbringing and education on vocational development activities

- Presenting multiple learning opportunities, suitable for everybody

- Managing ability and educational study guiding and determining the habits to learn for a long time

Parameter 3: Educational organizing

Indices:

- having skill to create learn-educate environment for effective learning

- using multiple intelligent theories and information ethnology effects on educating and learning

- learning strategies developing ability

Parameter 4: Education evaluation

Indices:

- Ability to use error concepts and valid concepts of evaluation to make or choose the evaluation

- Skill to choose the methods for suitable evaluation for educations related to teaching

- Skill to tell the evacuation results to the student and the others

Parameter 5: Consultation

Indices:

- Ability to analyze and recognize questions, problems and deduction

- Ability to experiment or feel all human emotions like sadness, hope luck and serendipity feel, sincerity

- Ability to speak in the mass, speak in front of the others

Parameter 6: Education control

Indices:

- Making the standards for students' behaviors in a class

- Detecting and /or developing a system for recording class progress and each student's progress

Parameter 7: Researching

- Having political and researching ethic

- Ability to cooperate and to make the researching networks.

- Ability to reinforce the researching competencies, especially related to effectiveness and interdisciplinary studies

\subsection{Skill Dimension}

Parameter 1: Perceptual

- Ability to percept and analyze the complex grower problems

- Ability to percept the environmental problems and to recognize and analyze within and out of the environment

- Mind and physical ability

- To recognize and percept self-status for realizing the organization goal and targets

Parameter 2: Human

- Ability to communicate friendly

- Ability to solve the group problems and make a cooperative environment among students 
- Ability to make good relationships with all persons

Parameter 3: Technical (knowledge and awareness)

- Awareness of physical and social development patterns among the students

- Ability to detect knowledge and /or students' skill for educational goals by using detection test, watching, and student's mote

- Choosing and developing the needed cases in order for the educational goals and students' learning needs

Parameter 4: Problem solving

- Ability to define the question

- Ability to make substitution and solutions

- Ability to decide about what is the best solution

- Ability to perform and execute the solutions and evaluate the results

- Ability of finishing the solution, resulting, and concluding

Parameter 5: Goal making

- Ability to make operational challenging goal

- Ability to harmonize short-time and long-time goals

- Ability to harmonize the previous goals with new conditions and new data's

5.3 Ethical Dimension

Parameter 1: Belief

- Paying attention to religious believes at work

- Working in line with God's Sake and Satisfaction

- Considering God in all affairs

- Enjoining good and forbidding wrong beliefs

- Origin of the universe and the hereafter (afterlife) beliefs

- Responsibility before God and Islam

Parameter 2: Islamic behavior

- Having Islamic ethics in the university environment

- Attention to Islamic ethics and governmental Islamic values

Parameter 3: Responsibility

- Being at the correct time at sessions, appointments, and classes

- Responsibility to do the duties in work

- Sensibility to the organization further and fate

- Seriousness and speed in the works and duties

Parameter 4: Islamic educational environment reinforcement

- Trying to perform fundamentals of religion and beliefs

- Trying to train Good humans

- Trying to prepare good environment for religious training and university ethical growth

- Trying to transform to practical Muslim teacher pattern

Parameter 5: justice

- Behavior in the justice way is equal to all students and colleagues

- Considering the rights and performing the justice

- Respecting the self-rights and the others' rights

5.4 Role Dimension

Parameter 1: Decision 
- Using awareness procedure and logical procedure at the decision

- To be calm at quick decisions

- Consulting with the others for deciding

- Thinking about the future and seeing all the advantages and disadvantages of the made decisions

- Having strong precept for answering and being responsible to decisions and works

Parameter 2: Critics management

- Ability to plan to prevent in the conditions of the time of criticism

- Ability to organize and manage the resources that are required to answer the critics

- Ability to form and lead the critic team

- Ability of helping the others after answering the critics

- Ability to make the executing orders against the critics

- Ability to communicate with the stakeholders to inform them of the critic results and affections

Parameter 3: Relation and communication

- Ability to logically give the data in a special subject

- Ability to wright simply and logically in the suitable formation and structure and in an easy to understand way for all readers

- Ability to read, study, and percept the special cases, and interpret the communications and group work skills

Parameter 4: Information

- Effective performing of all rules and orders

- Using valid and various data references

- Using data to learn in the lifetime

- $\quad$ Propagating the useable and effected data

5.5 Personnel Dimension and Sole Dimension

Parameter 1: Stimulus

- Feeling safe and having nothing to worry about the mistakes

- Ability to finish the started jobs

- Job and position of job satisfactory

- Doing works and jobs alone and solely

Parameter 2: Creativity and invention

- Being comfortable with changes

- Ability to design the environment that stimulates creativity and new thoughts

- Showing creativity and invention intelligence to increase the level of invention

Parameter 3: Elites gift from God

- Ability to percept comprehension and resulting and deduction and proving the texts

- Ability to percept the text inter-conceptual and education and analysis of them

- Ability to find the correlations and rules between changing parameters

- Ability to do numerical method calculations and mathematics

Parameter 4: Self-management

- Having the special goals righted to perform

- Self- encourage after successful jobs

- Thinking to self-beliefs and self-assumptions at the time of difficult conditions

- To open the assumptions and evaluate them in case of regretting by the others 
Parameter 5: Compatibility

- Job condition satisfactory and disliking to change the job

- Ability to accept leader's role and duty at social planning and extracting the person's work as a session boss, team group

In the case, the compatibility of results in this study with last research results is compared:

As we mentioned, we detected five main dimensions for the faculty competencies including parameters and sub parameters like the history and literature of the study. The results of the same studies in outside and inside the boundaries of Iran in this field are as follows:

It is necessary to mention that the advantages of this study are viewpoints to define the faculty competencies using 360-degree feedback that are completely updated and suitable for the current status of our country.

1) In the first dimension, the case of faculty competency model is performance:

Seven parameters of planning, leading, organizing, monitoring, evaluation, consultation, and researching are defined by the help of fact oral analysis and after evaluating the history, we realized the upper parameters in the researches of these men: Cheetham and Chivers (1996), Vishan (1999), Robert et al. (2009), Rouhollahi et al. (2004), Jahanian (2013), and Arasteh and Mahmoudi (2003).

2) In the second dimension, as following, the case of faculty competency model is skill:

Five parameters of perceptual, humanity, technical, problem solving, and making goals are defined by the oral fact analysis; and with evaluating the history, we realized that these parameters had been brought in the studies of these men: Sylvia and Horn (2009), Jafari et al. (2009), Khadivar (2009), and Gorji \& Siami (2008).

$3)$ In the third dimension, as following, the case of faculty competency model is ethical dimension:

Five parameters: faith and belief, Islamic behavior, responsibility, reinforcement of Islamic educational environment, and justice are defined by the oral fact analysis; and with evaluating the history, we realized that these parameters had been brought in the studies of these men: W. Brad Jonson (2003), Hedayat \& Jafari (2014), Moradi-Doliskani (2014), Chitsaz (2011), Movahed \& Saqebi (2009), Torkman-Nezhad (2009).

4) In the fourth dimension, as following, the case of faculty competency model is duty and role:

Five parameters of descriptive, information, communication, critic management, and consultation are defined by oral fact analysis; and with evaluation of the history, we realized that these parameters had been brought in the study of these men: Olivia and Henson (2011), Brightman, Elliot, and Bhada (1993), and Asefzade (2009).

5) In the fifth dimension, as following, the case of faculty competency model that is personnel sole:

Five parameters of producing stimulus, creativity and inventing brilliance, self-management, and compatibility are defined by the oral fact analysis; and with evaluation the history, we realized that these parameters had been brought in the study of these men: Patrick and Smart (1989), Fatehi (2013), Jezni et al. (2009), Ebrahim-Qaram et al. (2009), and Hosseini et al. (2009).

The Second Question of the Research:

How is the current status of the parameters in the faculty of university?

In the evaluation of faculty competency in Islamic Azad University branches of Fars province, and evaluating the results of Wilcoxon test, we understood that all dimensions of faculty sufficiency were suitable and appropriate. For grading the dimensions of competency and grading the sub parameters of competency dimensions, we used freedman degree test that came to the results as follows:

Table 4. Grading result of faculty competency dimensions

\begin{tabular}{lc}
\hline Faculty competency dimensions & Average grade \\
\hline Performance & 1.38 \\
Skill & 3.95 \\
Ethical & 3.63 \\
Duty & 2.92 \\
Personal & 2.65 \\
\hline
\end{tabular}

According to the above table, the maximum priority belongs to the skill dimension and the minimum priority 
belongs to the performance dimension (Appendices paper).

Table 5. Grading results of sub parameters of the performance dimension:

\begin{tabular}{lc}
\hline Sub parameter of the performance dimension & Average grade \\
\hline Educational & 3.02 \\
Educational laddering & 4.36 \\
Educational organizing & 4.04 \\
Consultation & 5.09 \\
Educational monitoring & 5.09 \\
Researching & 3.56 \\
\hline
\end{tabular}

According to the above table, the maximum priority belongs to monitoring dimension and the minimum priority belongs to planning dimension.

Table 6. The results of grading the skill dimension sub parameter

\begin{tabular}{lc}
\hline Skill dimension sub parameter & Average grade \\
\hline Conceptual & 3.08 \\
Human & 2.85 \\
Technical & 3.17 \\
Problem solving & 3.78 \\
Goal making & 2.12 \\
\hline
\end{tabular}

Maximum priority: Problem-solving sub-parameter

Minimum priority: goal-making sub-parameter

Table 7. The result of grading the ethical dimension sub parameter:

\begin{tabular}{lc}
\hline Skill dimension sub parameter & Average grade \\
\hline Faith and belief & 3.02 \\
Islamic behavior & 2.86 \\
Responsibility & 2.80 \\
Islamic education environment reinforcement & 2.77 \\
Justice & 3.55 \\
\hline
\end{tabular}

Maximum priority: faith and belief sub parameter

Minimum priority: justice sub parameter

Table 8. Grading results of duty dimension sub parameter

\begin{tabular}{lc}
\hline Duty dimension sub parameter & Average grade \\
\hline Decision making & 2.66 \\
Critic management & 2.97 \\
Communication & 2.96 \\
Data-information & 3.88 \\
Consultation & 2.52 \\
\hline
\end{tabular}

Maximum priority: data and information sub parameter

Minimum priority: consultation sub parameter 
Table 9. Grading results of personnel sub parameter

\begin{tabular}{lc}
\hline Personnel sub parameter & Average grade \\
\hline Stimulus & 2.72 \\
Creativity and inventing & 2.89 \\
Elite-ness & 2.96 \\
Self-managing & 3.88 \\
Compatibility & 2.55 \\
\hline
\end{tabular}

Maximum priority: self-managing sub parameter

Minimum priority: compatibility sub parameter

The Third Question of the Study:

What is the level of coordination degree of the proposed model from the viewpoint of specialists?

To answer this study question, the designed model associated with details was given to eleven professors. Nine professors verified the model and the others believed that some other effective dimensions existed and should be considered.

Thus, according to these offers and suggestions, $90 \%$ percent of specialists verified the above model and its validity.

Moreover, it is a suitable tool for evaluating the faculty sufficiency.

\section{Conclusion}

Today, the humankind society development is in a close relationship with the outputs of higher education. One of the big challenges that today higher education systems have is the quality and its promotion, improvement, and guarantee. Every organization that can determine the quality, measure it, and reach it, has gained a competitive advantage and can stable the organization with this tool.

According to the international quality test network in higher education, quality is evaluating higher education with some standards (indices detected before) duty, goals, and respects.

For designing favorable higher education system in Iran, according to Iranian Islamic civilization pattern, they have tried to protect Islamic university values and ethics practically.

To achieve these goals with attention to Islamic Iranian backgrounds, universities move to sufficient system like viewpoints of the Islamic system's leader. Meritocracy requires some scientific and political considerations that can be summarized into five indices; sufficient upbringing, sufficient detecting, sufficient choosing, sufficient wanting, sufficient protecting; and the first step for having meritocracy system is to define sufficiency.

In this study, the researcher has tried to evaluate the faculty sufficiency in a different way as well as trying to draw and illustrate dimensions, parameters and indices to prepare the improvement of quality and higher education progress.

According to the results from the study, choosing and hiring sufficient faculty in the higher education system and especially in the Islamic Azad University is very important and guarantees achieving and accessing to the organizations goals and targets. General model of competency evaluation in the various parts of the country like government part can increase quality, improvement, and development of the organization. Finding the updated indexes of faculty competencies evaluation refers to updated models and using the results in a practical way; in fact, the steps are toward above goals and targets. According to the study, we recommend doing these studies:

1) Evaluating and determining the competence of faculty of the other academic regions.

2) Evaluating and comparing the faculty competence in Iran with the other developed countries.

3) Preparing field helps, financial helps, and support in fundamental researches and practical studies related to the competence development and the educational factors and items.

4) Evaluating the requirements of education at regional needed competence.

5) Evaluating all (the other) effective parameters on competences development.

\section{References}

Arasteh, H. R. (2005). How do the universities work? Higher education planning and research institute. 
Arasteh, H. R., \& Mahmoudi, M. (2003). Effective education: An approach based on teaching evaluation by students. Scientific Journal of Medical Sciences University of Semnan, the 5th book.

Asefzade, S. (2009). The most important ability of medic professors from faculty members' viewpoint. The $10^{\text {th }}$ vernacular congress of education in medical sciences (p. 12), Shiraz, Medical Sciences University of Shiraz.

Bazargan, A. (2005). Steps of planning higher education development and its evaluation, management knowledge administrative and trading management. University of Tehran, No. 9, 10 (summer and autumn 55-56).

Brightman, H. J., Elliot, M. L., \& Bhada, Y. (1993). Increasing the effectiveness of student evaluation of instructor data. Decision Sciences, 24(1), 192-199. https://doi.org/10.1111/j.1540-5915.1993.tb00469.x

Cheetham, G., \& Chivers, G. (1996). Towards a holistic model of professional competence. Journal of European Industrial Training, 20(5), 20-30. https://doi.org/10.1108/03090599610119692

Chitsaz, E. (2011). Faculty members' competency pattern for social planning and cultural studies office. Publication of Ministry of science, researches and technology.

Ebrahim-Qaram, S. et al. (2009). Creative teacher. The $10^{\text {th }}$ vernacular education congress in medical sciences, (p. 23), Shiraz, Shiraz Medical Sciences University.

Fatehi, R. (2013). Tehran and Alborz, Jahad Keshavarzi Education Centers' Teachers Vocational Efficiencies Evaluation (M.A. thesis).

Ferasatkhah, M. (2009). Higher education and university, global views on Iran's problems. Ney publication

Gorji, M. B., \& Siami, S. (2008). Islamic Azad University faculty members' performance criterion. Quarterly of Detection Management, 5(11).

Hojati, M. B. (1999). Islamic education and training mores. Sadra Publication.

Hosseini, M. A. (2009). Favorable properties of a teacher from the viewpoint of university faculty members. The $10^{\text {th }}$ country congress in medical sciences education (p. 22), Shiraz, Shiraz University of Medical Science.

Jafari, H. (2014). Design and psychometry of evaluating tool for nursing faculty members' vocational competency ( $\mathrm{PhD}$ thesis, Iran doc).

Jafari, M. (2009). Scrutiny communication skills of faculty member in one of the $2^{\text {nd }}$ brigade universities. The $10^{\text {th }}$ country congress of education in medical sciences (p. 18), Shiraz University of Medical Sciences.

Jahanian, R. (2013). Educational and researching performance evaluation of Tehran-central Islamic Azad University faculty members. Journal of Training, Islamic Azad University, Branch of Bojnord, No. 33.

Jebeli, S. (2004). Effect of performance evaluation of personnel on the promotion of the efficiency level, M.A. Thesis, Islamic Azad University, Sciences and researches Branch, Tehran.

Johnson, W. B. (2003). A framework for conceptualizing competence to mentor. Ethics \& Behavior, 13(2), $127-151$

Kember, A., \& Jones, C. (1996). A global perspective on educational goals, Teaching and evaluation. Rutledge publication.

Khadivar, Z. T. (2009). Styles, habits, and skills at work of strong teachers, what are those? The $10^{\text {th }}$ country congress in medical sciences education (p. 24), Shiraz, Shiraz University of Medical Sciences.

Moradi-Douliskani, M. (2014). Parameters detection and standards of Islamic education of teachers teaching vocational ethics (M.A. thesis, Iran doc).

Mousapour, N. (2002). Evaluation patterns of theoretical fundamentals. Quarterly of Higher education planning and research, 23.

Movahed, S. Y., \& Saqebi, R. (2009). Scrutiny on vocational ethics principles from the wise doctor and the strong professor, Mohammad Hussein Aqili Shirazi's viewpoints. $10^{\text {th }}$ country education congress in medical sciences (p. 18), Shiraz, Shiraz medical Sciences University.

Noorshahi, N. (2008). Place and rank of Iran in education, research and innovation. Tehran, Institute of Higher education planning and research.

Olivia, P. F., \& Henson, K. T. (1980). What are the essential generic teaching competencies? Theory into practice, 19(2), 117. https://doi.org/10.1080/00405848009542884 
Patrick, J., \& Smart, R. M. (1998). An Empirical Evaluation of Teacher Effectiveness: The Emergence of Three Critical Factors. Assessment \& Evaluation in Higher Education, 23(2), 165-178. http://doi.org/10.1080/0260293980230205

Rouhollahi, A. A. et al. (2014), Effective factor of detection of faculty members' performance evaluation from teh viewpoint of students. Journal of Police Education Management Studies, 7(4).

Sarmad, Z., Bazargan, A., \& Hejazi, E. (1999). Behavioral sciences research method. Tehran, Agah publication.

Smith, Z. A. (2010). Higher education leadership competencies: Quantitatively refining a qualitative model. Journal of leadership \& organizational studies, 17(1), 61-70.

Sylvia, C., \& Horn, M. C. (2009). A framework of values, skills and knowledge for initial teachers. Australian Journal of teacher education, 34(3).

Torkman-Nezhad, S. (2009). Wise professor. The $10^{\text {th }}$ country congress of education in medical sciences (p. 10), Shiraz, Medical Sciences University of Shiraz.

Vishan, H. A. (1999). A study of effective teaching skills of preservice student teacher as perceived by cooperating teachers and university supervisors in Jordan ( $\mathrm{PhD}$ dissertation, Ohio University).

\section{Appendix}

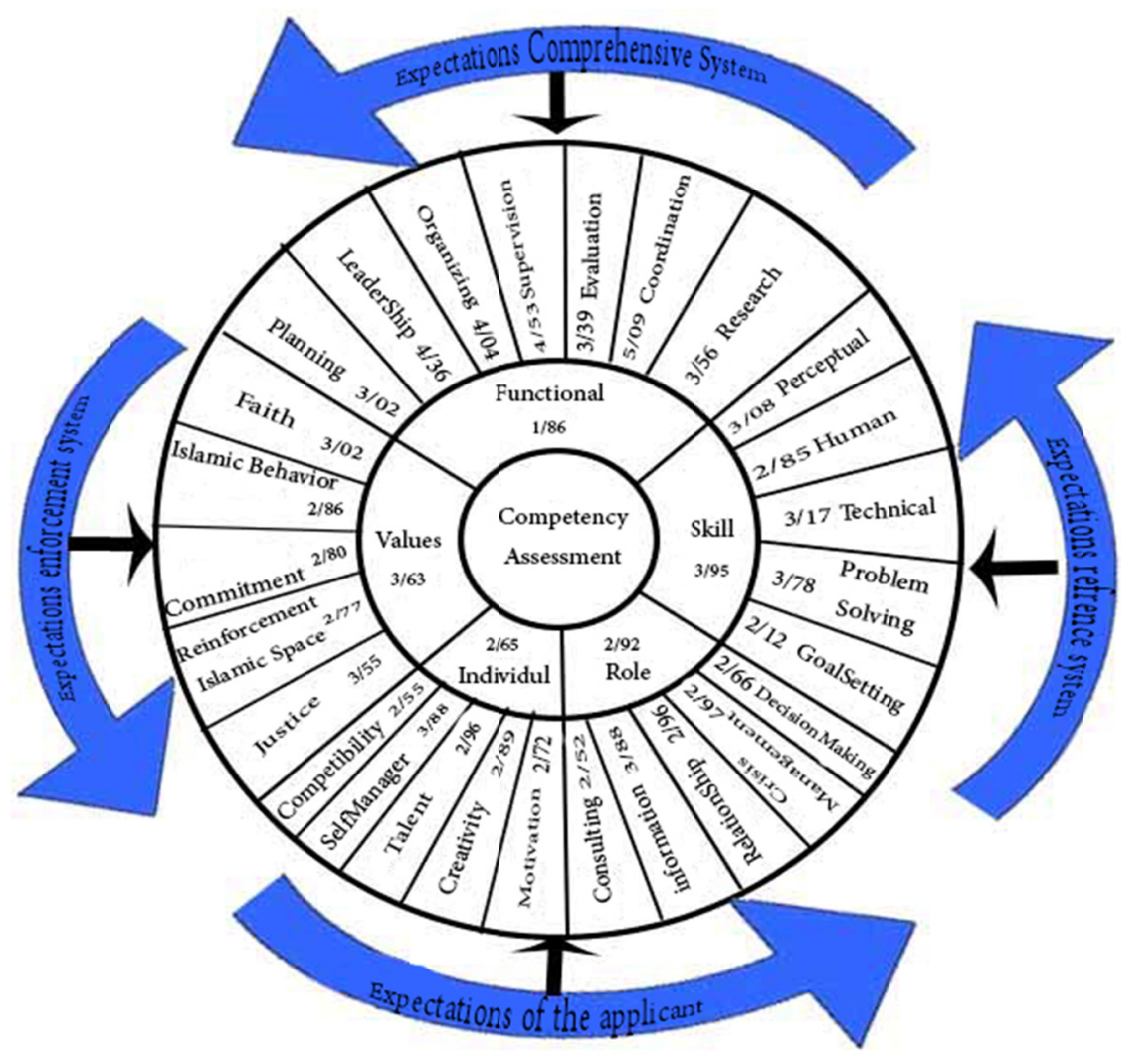

Competence assessment model of the faculty

\section{Copyrights}

Copyright for this article is retained by the author(s), with first publication rights granted to the journal.

This is an open-access article distributed under the terms and conditions of the Creative Commons Attribution license (http://creativecommons.org/licenses/by/4.0/). 